\title{
Aspekti dušobrižništva u Katoličkoj crkvi danas
}

\author{
Andreja Sršen*
}

\begin{abstract}
Sažetak
U radu se razmatraju opća načela Katoličke crkve i njezina crkvenoga djelovanja u pastoralnoj skrbi za selioce, razlikujući uzroke političke, ekonomske i kulturne naravi selidbe, te stavljajući dostojanstvo osobe kao temeljno pravo. Uloga i perspektiva hrvatske inozemne pastve i njezine duhovne mreže u svijetu, predstavlja njezinu veliku odgovornost s obzirom na sve opsežniji proces sekularizacije u svijetu koji ne pretpostavlja samo društveno-objektivne posljedice, nego i individualno-subjektivne. U tom smislu djelovanje hrvatske inozemne pastve ne može se ispravno ocijeniti i opisati isključivo u optici dokumenata koji reguliraju pastoralnu skrb među katoličkim migrantima jer danas imamo i niz različitih društveno uvjetovanih čimbenika koji definiraju njezino djelovanje. U tom kontekstu ona danas ima posebnu ulogu u odnosu prema traženju novih oblika zaštite selilaca, kao i njihovih vrijednosti koje donose sa sobom u novu sredinu.
\end{abstract}

Ključne riječi: Katolička crkva; Evanđelje; dušobrižničko djelovanje; selilaštvo; domovina; inozemna pastva.

\section{Uvod}

Iz višestoljetne migracije Hrvata, kako kroz povijest, tako i danas, kroz različita djelovanja nazočna je Katolička crkva. Povijesno gledano, već su se za vrijeme pape Leona XIII. od 1887. godine počeli izdavati dokumenti o brizi za katoličke iseljenike, no sustavnija briga Katoličke crkve započinje 15. kolovoza 1912. godine, kada je papa Pijo X. svojim motuproprijem De Catholicorum in exteras regiones emigratione, Cum omnes Catholicos odredio da se pri Svetoj konzistorijalnoj kongregaciji osnuje Ured za duhovnu skrb katoličkih iseljenika, čija je zadaća bila duhovna pastva i skrb o poboljšanju životnih prilika iseljenika (Stanković, 1980). Dokumenti koji se i danas smatraju temeljima u zakonodavstvu za pastvu iseljenika, a koji su izišli u vrijeme upravljanja Katoličkom crkvom pape Pavla VI., su motuproprio Pastoralis migratorum cura i Instructio de pasto-

Doc. dr. sc. Andreja Sršen, Hrvatski studiji Sveučilišta u Zagrebu, Odsjek za sociologiju. Adresa: Borongajska cesta 83d, 10000 Zagreb, Hrvatska. E-adresa: srsen.andreja@gmail.com 
rali migratorum cura ("Uputa o pastoralnoj brizi za migrante") od 20. kolovoza 1969. godine. ${ }^{1}$

U tom smislu, imajući u vidu nove procese migracija u svijetu, dušobrižničko djelovanje Katoličke crkve danas možemo svesti pod misionarsku, karitativnu praksu i socijalni pastoral. Dušobrižništvo kroz misionarsko djelovanje danas dobiva na značenju u različitim sferama društvenoga života, gdje od oblika njegova djelovanja u očuvanju njegovanja kulturne tradicije, svakako je najznačajnije ono na polju obrazovanja u župnim školama. Načelo vjernosti izvornoj kulturi s mogućnošću otvaranja i prihvaćanja kulture "posvojenja" odgovornost je svakoga misionara. Unutar suvremene pojave selilaštva, koja ima svoje biblijske korijene, ${ }^{2}$ Katolička je crkva svjesna da je to danas veliki ispit savjesti za one koji sele, ali i za one koji ih primaju.

Imajući u vidu da je Katolička crkva uvijek odgovarala na takve izazove, kako kroz povijest, pa tako to čini i danas, njezinu ulogu u tim procesima stavljamo u novi socijalni prostor umreženoga društva. Današnje poimanje umreženoga društva, prema sociologu Emanuelu Castellsu, uključuje prožimanje različitih civilizacija, rasa, ideologija i kultura. Granice tih pojmova teže prema iščezavanju, a prostor i prostorne kategorije ulaze u novu formu socijalnoga polja (Castells, 2000). To unosi novu dimenziju crkvenoga djelovanja gdje Crkva i njezina duhovna sveobuhvatnost postaje misionarska za one koji Boga ne poznaju, kao i za one koji ga traže. Selioce u tom kontekstu Crkva uvijek treba sagledavati u različitim dimenzijama njihova kompleksnoga života, uvažavajući dostojanstvo svakoga pojedinca, što se posebno ističe u dokumentu Welcoming Christ in Refugees and Forcibly Displaced Persons Pastoral Guidelines (Welcoming Christ, 2013). Upravo se u tom dokumentu posebno naglašava kako je važno njegovati solidarnost kao osjećaj zajedničkoga pripadanja gdje su svi ljudi dio jedne zajedničke uljudbene porodice u kojoj pojedinci, neovisno o vjeri, etničkoj pripadnosti ili rasi, imaju jednaka prava na dostojanstveni život, kao i prava na zaštitu istoga (Welcoming Christ, 2013). Imajući u vidu nove fenomene migracija, dokument The Instruction: Erga migrantes caritas Christi (Erga migrantes caritas Christi, 2004) posebno navodi kako pastoralna skrb za migrante treba biti odraz Kristove ljubavi, koja je dana svima. Upravo na tom tragu treba tražiti nova rješenja akulturacije migranata u njihovoj novoj sredini, koja mora biti prilika za nove vrste dijaloga, kako se navodi u dokumentu (Erga migrantes caritas Christi, 2004). Svi ti dokumenti, koji predstavljaju Učiteljstvo Crkve, potvrđuju kako novi društveni odnosi, kao posljedica suvremenih geopolitičkih kretanja, predstavljaju ne samo izazov za

1 Ti su dokumenti zamijenili apostolsku konstituciju Exsul Familia jer su prilike u svijetu i zaključci Drugoga vatikanskoga koncila to zahtijevali. Upravo je apostolska konstitucija Exsul Familia najveće djelo pape Pija XII. na području zalaganja za prava iseljenika i poratnih izbjeglica, a papa Pijo XII. potpisao ju je 1. kolovoza 1952. godine (Stanković, 1980).

2 Giacomo Danesi, iznoseći biblijske korijene suvremene teologije navodi mjesta u Starom zavjetu »koja govore ne samo o Božjem narodu na putu nego i o bratu strancu koji se u tom narodu nađe i kome se od početka jamče sasvim određena prava. U Novom zavjetu poimanje bratstva širi se prema ukidanju pojma i stvarnosti stranca« (Stanković, 1980, 15). 
Crkvu, koja ulaže velike napore kako bi svaki migrant bio prihvaćen u punini ljudskoga dostojanstva, te onaj koji povezuje društva, narode i nacije, stvarajući tako nove oblike društvenoga povezivanja, nego je to izazov i za nove oblike međureligijskoga djelovanja.

\section{Katoličke misije i transnacionalni socijalni prostori}

\subsection{Transnacionalna perspektiva}

Uzimajući hrvatske katoličke misije u predmet analize, dobivamo pojavu seljenja uzrokovanu suvremenim političkim, ekonomskim i kulturnim čimbenicima, i novo socijalno polje, okruženo različitom tipizacijom odnosa koji definiraju novu društvenu funkciju katoličkih misija danas. Ovdje treba naglasiti neke važne elemente za razumijevanje uloge katoličkih misija u poimanju sveobuhvatne raščlambe selilaštva, uvažavajući njegovu složenost.

Prvo, unutar društvenih znanosti, napose kada je riječ o migracijskim studijama, sve je rasprostranjenija transnacionalna perspektiva, koja uključuje svijest o neprikladnosti koncipiranja društvenih i nacionalnih granica kao podudarnih (usp. Kuti, 2012; Božić, 2004; Mesić, 2007). Iako su pojmovi transnacionalizma i transnacionalnoga socijalnoga prostora još uvijek nedovoljno razrađeni zbog svoje višeznačnosti, nedovoljne teorijske ukorijenjenosti, ipak njihova znanstveno-istraživačka perspektiva sve više dolazi do izražaja unutar novih istraživačkih koncepata, kao što je analiza katoličkih misija u odnosu na različite jedinice analize: od pojedinca i mreža, preko grupa i institucija. U tom kontekstu treba naglasiti da Katolička crkva, koja je i univerzalna i misionarska, danas mora za potrebe selilaca imati "Crkvu iseljenja”, ali i "Crkvu doseljenja".

Drugo, u želji da se postigne interdisciplinarni konsenzus oko pojma transnacionalizma treba prvo naznačiti odnos nacije i države. U tom smislu autori Waldinger i Fitzgerald $(2004,1182)$, ističu da »mnoge od najutjecajnijih studija imigrantskoga transnacionalizma [...] zapravo istražuju transdržavne veze između određenih mjesta ovdje i tamo«. Iz toga proizlaze i novi poticaji istraživanja uzajamne suradnje Crkve iseljenja i Crkve doseljenja, kanalizirajući u najpozitivnijem smislu napetosti koje se obično javljaju na relaciji domovinstva i izvandomovinstva.

Pristup inkorporacije useljenika domovinskoj orijentaciji neki teoretičari smatraju neopravdanim jer održavanje transnacionalnih veza i integracija u socijalne odnose nacionalnih društava autorice Levitt i Glick Schiller tumače kroz distinkciju načina bivanja (ways of being), koji se odnosi na »stvarne socijalne odnose i prakse«, i načina pripadanja (ways of belonging), koji se odnose na akcije koje označavaju identitet kao »svjesnu povezanost s određenom grupom « (Levitt i Glick Schiller, 2004, 1010). Upravo te autorice u istraživanjima selilaštva koriste termin "transnacionalna socijalna polja" definirajući ih kao multidimenzionalna jer »obuhvaćaju strukturirane interakcije različitih oblika, dubine i širine koje se u društvenoj teoriji razlikuju terminima poput organizacije, institucije i soci- 
jalnog pokreta (Levitt i Glick Schiller, 2004, 1009). Tako koncipirana socijalna polja zanimljiva su za relevantnost istraživanja uloge hrvatskih katoličkih misija, koje su integrirani dio Katoličke crkve, kao i za istraživanja o "iseljenoj Hrvatskoj”, koja je predmet istraživanja izvan granica nacije-države. Ovdje treba spomenuti i primjenjivost termina simultanost, koji autorice uvode. Termin koriste kako bi različite sfere i prakse useljenika, unutar sociološkoga teoretiziranja i empirijskoga istraživanja, prikazale kao sustavno istraživanje načina života koji uključuje dnevne rutine, aktivnosti i institucije u "zemlji destinacije" (Levitt i Glick Schiller, 2004, 1003).

\subsection{Priesov pojam transnacionalnoga socijalnoga prostora}

Za temeljne rasprave o transnacionalnim socijalnim prostorima, gdje smještamo djelovanje hrvatskih katoličkih misija, uzimamo tipologiju Priesova pojma transnacionalnoga socijalnoga prostora (Pries, 2001) zbog njegova analitičkoga aspekta socijalnih praksi, simboličkih sustava i artefakata koji su uvijek sadržani u socijalnom prostoru kao neovisne konfiguracije (Pries, 2008b). Imajući u vidu da Katoličku crkvu karakterizira čvrsta organizacijska struktura, Pries za potrebe istraživanja takvih fenomena (Pries, 2008a) daje nadogradnju pojmu transnacionalnoga socijalnoga prostora prema određenim dimenzijama koje su određene "prema stupnju institucionalizacije, fiksiranosti ili jakosti, kao i prema općenitom sociološkom shvaćanju « (Pries, 2005, 180). U prvom tipu, koji se odnosi na sociologiju svakodnevnoga života, ulaze predvidivi obrasci ponašanja, a u drugom se tipu pojavljuju transnacionalne organizacije koje prema Priesu predstavljaju »stabilne i guste lokuse kooperacije i interakcije s pravilima članstva, danim strukturama i procesima te iskazanim ciljevima i svrhama (Pries, 2005, 180). U trećem tipu pojavljuju se transnacionalne institucije kao »kompleksni okviri rutina, pravila i normi koji strukturiraju značajne sfere života« (Pries, 2005, 180). Upravo katoličke misije odgovaraju drugoj i trećoj razini analize, i to od mikrorazine, koja uključuje svakodnevne rituale, kao što je molitva i odlazak na misu, do makrorazine, koja uključuje ulogu institucija, što se u ovom predmetu analize može primijeniti na instituciju Katoličke crkve. U tom se kontekstu i katoličke misije mogu razmatrati kao institucije koje djeluju u polju transnacionalnoga socijalnoga prostora, odnosno izvan granica nacija-država, te kao takve predstavljaju određenu socijalnu morfologiju religijskoga transnacionalizama s jakom konfiguracijom socijalnih praksi.

Konačno, vrijedno je istaknuti činjenicu da su navedeni autori Pries, Levitt i Glick Schiller uvođenjem novih koncepata i pojmova nastojali razviti nove indikatore istraživanja, kao i njihovu provjeru empirijske relevantnosti koncepata, gdje pojam katoličkih misija, unutar navedenih teorijskih koncepata, češće ostaje na razini aktera i njihovih praksi, što ne isključuje jednako važne simboličke veze unutar pokušaja integracije pojmova socijalnoga kapitala i mreža kroz različite definicije socijalnoga prostora, gdje se određuje važnost katoličkih misija kao središta vjerskoga i društveno-nacionalnoga života. 


\section{Novi izazovi dušobrižništva u suvremenim prilikama selilaštva}

\subsection{Pastoralna skrb}

Hrvatske katoličke misije diljem svijeta nastale su kao izraz duhovne brige Katoličke crkve o svojim iseljenim članovima — vjernicima, te su kao takve postale nositeljima, ne samo duhovnoga života iseljenih Hrvata, nego kulturnoga i društvenoga života, pa kao takve predstavljaju nezaobilazni dio izučavanja hrvatskoga iseljeništva s obzirom na onu dimenziju bez koje se hrvatsko iseljeništvo jednostavno ne može zamisliti, a to je dušobrižništvo.

Kada je riječ o hrvatskoj inozemnoj pastvi, moramo odgovoriti, prije svega, što to pastorizacija jest, kako bismo odredili i važnost njezina značenja za hrvatsku nacionalnu svijest, tradiciju i kulturu u okviru institucionalne religijske prakse. U većini teorijskih pristupa institucionalna religijska praksa svakako predstavlja jedan od važnih indikatora tradicionalnih oblika religioznosti (Kalmijn, 2003). Prema autorici Hervieu-Léger, koja promatra religiju kao "lanac sjećanja”, religija je ona poveznica koja čini individualnoga vjernika pripadnikom zajednice koja okuplja prošle, sadašnje i buduće članove, te dio tradicije (kolektivnoga sjećanja) koja postaje temelj života zajednice (Hervieu-Léger, 2000; Iannaccone, 1992). U tom okviru smještamo i pastorizaciju. Središnja je točka pastorizacije nedjeljna misa, koja ima, uz vjersko, i sociološko značenje jer se tada stvara krug interakcije među poznanicima, prijateljima i rodbinom. Uz misu, koja ima primarno vjersko značenje, tu posebnu važnost imaju obredi krštenja i vjenčanja. Naravno, religiju tu promatramo ne samo kao vezivanje za crkvene institucije, nego i kao interpretaciju života i načina osmišljavanja iskustava, te zaštićivanja zajedničkih vrijednosti, ali i suočavanja sa socijalnim promjenama s kojima se susreću doseljenici. Tako nije nebitna činjenica koliko jedna hrvatska katolička misija ima krštenja, vjenčanja i sprovoda, jer nam ti podatci govore o potrebi pastoralne skrbi na određenom području, ili primjerice, o povećanju ili smanjenju vjernika katolika. Pastoralna skrb ima zadaću povesti brigu o trajnim problemima selilaca koje izaziva pojava seljenja kao što su briga za duhovnu, ali i nerijetko materijalnu skrb, napose kada pod različitim pritiscima, što ekonomskim, što obiteljskim, vjerska praksa u iseljeništvu ima tendenciju da oslabi ili da se čak potpuno ugasi. Naime, selioci se često nađu bez crkve i svećenika, bez svojega materinskoga jezika i obreda. Da bi to spriječila, Katolička se crkva unutar misionarskoga djelovanja prilagodila specifičnim potrebama bilo pojedinaca bilo određenih skupina unutar doseljeničkih zajednica sukladno Uputama o pastoralnoj brizi za migrante. Naime, Uputa o pastoralnoj brizi za migrante (De pastorali migratorum cura), koju je 15. kolovoza 1969. objavila Sveta kongregacija za biskupe, predstavlja jedan od temeljnih dokumenata vjerskoga djelovanja Crkve u iseljeništvu. ${ }^{3}$ Uputa određuje dužnosti i nadležnosti Svete Stolice, biskupskih konferencija, mjesnih

3 S ciljem očuvanja vjere i vjernika Crkva je stvorila čitav ustroj ustanova koje se brinu za pastoral migranata. Na vrhu je Papinsko vijeće za "dušobrižništvo selilaca" s odsjecima za pojedine kategorije "svijet u pokretu". Potom slijede nacionalne biskupske konferencije sa svojim vijećima 
biskupa i svećenika koji se posvećuju dušobrižništvu selilaca. U tom smislu, Uputa je odraz traženja novih oblika zaštite selilaca, kao i njihovih vrijednosti koje donose sa sobom u novu sredinu.

\subsection{Društvena i kulturalna analiza}

Kako se produbilo uvjerenje da seljenje nije tek privremena pojava, sagledavajući ju u suvremenom kontekstu, nego da je to trajna pojava hrvatskoga društva koja je označena općom pokretljivošću, posebno mjesto u dušobrižničkom djelovanju zauzimaju mladi. Nova sredina u koju se dolazi traži nove prilagodbe. Problemi mladih doseljenika Hrvata katolika posebno su bitni jer se s njima ne susreće samo država u koju dolaze, nego je to puno veći problem za cjelokupno hrvatsko društvo, kao i za Crkvu i njezino misijsko djelovanje. Tomu svakako treba posvetiti posebnu pozornost kulturalnoj analizi položaja suvremenoga hrvatskoga doseljenika, koji se je našao u novoj, nerijetko puno sekularnijoj sredini, tražeći bolje uvjete života, izloženoga dubokim socijalnim, psihološkim, moralnim i vjerskim promjenama koje izazivaju duboke neuravnoteženosti. On je čovjek u procjepu između tjeskobe i nade, i odraz suvremenoga hrvatskoga društva, koje karakteriziraju izrazite promjene u svim područjima društvenoga života. Sukladno tomu, pastoralni djelatnici se danas, napose imajući u vidu suvremeni trend iseljavanja mladih obitelji iz Hrvatske, susreću s novim problemima mladih koji ulaze u različite društvene i socijalne krize s obzirom na, često neočekivane, okolnosti koje nalaze po dolasku u novu zemlju. Odvajanje od roditeljske kuće, učenje novoga jezika, različite društvene okolnosti s kojima se moraju nositi cijele obitelji, često uzrokuju i različite tipove kriza, gdje misionari, uz duhovnu skrb, nerijetko daju i onu socijalnu. Njihova se posebna uloga danas očituje u očuvanju hrvatskoga nacionalnoga kulturnoga nasljeđa, napose jezika koji je najviše ugrožen. Sve te činjenice upućuju na zaključak kako hrvatske katoličke misije danas, s obzirom na nove migracijske procese koji imaju duboke socijalne, humanitarne, ekonomske i kulturne posljedice po zemlju iz koje se odlazi, ali i one u koju se dolazi, moraju nastojati da se sami selioci osjete kao navjestitelji Evanđelja. Dušobrižno služenje mora se promatrati kao pitanje vjernika i bogoštovlja povezanima s ljudskim problemima koje izaziva pojava seljenja.

\subsection{Suvremene prilike i perspektive inozemne pastve}

I kako god je budućnost nesigurna, usprkos nekim kriznim žarištima u Europi i svijetu, razvidna je dobra perspektiva hrvatske inozemne pastve i njezine duhovne mreže u svijetu, ali i njezina velika odgovornost, jer kako je kardinal Kuharić u molitveniku pjesmarici Slavimo Boga poželio hrvatskim katolicima da »sačuvaju vjeru i da ostanu Božji ljudi predajući i svojoj djeci baštinu bogoljublja, čovjekoljublja i rodoljublja«, danas bismo to mogli označiti kao najtežu zadaću

za pastoral migranata, ordinarijati sa svojim referadama za strance te na kraju etničke župe, dušobrižničke misije, obične misije i kapelanije (Stanković, 1991, 440). 
djelovanja hrvatske inozemne pastve s obzirom na proces sekularizacije u svijetu koji ne pretpostavlja samo društveno-objektivne posljedice, nego i individualnosubjektivne. ${ }^{4}$

Sagledavajući hrvatsku inozemnu pastvu s povijesnoga odmaka, otkrivamo izvornost ciljeva, intelektualni pristup, ali i novu teološko-povijesnu viziju misionara, koji danas mora približiti svakomu vjerniku novu kulturu i novo društveno okruženje, koje je, barem kada je riječ o hrvatskim katoličkim misijama u Europi, u većem dijelu zahvaćeno procesima sekularizacije. ${ }^{5} \mathrm{U}$ tom suodnosu društvenih i religijskih promjena u europskom kontekstu, misionari su danas pozvani na korištenje različitih polja društvenih znanosti, posebno teologije, psihologije i sociologije, kako bi se razjasnila kulturna situacija u kojoj trebaju navijestiti Evanđelje. Tu svakako treba istaknuti novi oblik crkvenoga društvenoga i kulturnoga dijaloga u kontekstu dokumenata Drugoga vatikanskoga koncila koje je Pavao VI. iznio u svojoj prvoj okružnici Ecclesiam suam: ${ }^{6}$ »Posebna je činjenica to što Crkva dok nastoji oživjeti svoj nutarnji život u Duhu Gospodinovu, razlikujući se i odvajajući se od profanog društva u koje je utopljena, ona se istovremeno pokazuje kao živi kvasac i sredstvo spasenja ovoga svijeta otkrivajući i jačajući svoj misionarski poziv, tj. svoje glavno poslanje, a to je učiniti od čovječanstva, u bilo kojoj situaciji se ono nalazilo, zanosni objekt svojeg evangelizacijskog poslanja « (Šimić, 2008, 807). ${ }^{7}$ Budući da danas vjera i kultura nailaze na različite društvene rascijepe, od suvremenoga misionara koji evangelizira zahtijeva se percepcija kulture usmjerena na primjenjivost religijskih normi i otkrivanje područja u koja Evanđelje treba prodrijeti. Razvojem modernoga društva dolazi do promjena, ne samo religijskih praksi i opadanja utjecaja religijskih institucija, nego prije svega dolazi do opadanja važnosti zajednice u visoko organiziranim društvenim sustavima.

Stoga, novo shvaćanje Katoličke crkve i njezina dušobrižničkoga djelovanja zauzima svoje mjesto u tumačenju značenja položaja čovjeka selioca u suvremenom svijetu. Upravo s takvim čovjekom koji živi u socio-psihološkom rascjepu, zadaća katoličkih misija i dalje ostaje da njegova integracija u novo društvo postane funkcionalna, socijalna, emocionalna i kulturalna.

4 Termini sekularno, sekularizam i sekularizacija izvode se iz latinske riječi saeculum, koja znači "ovo doba”, ali i "ovaj svijet”. Pojam sekularizacije danas se sve više upotrebljava u prenesenom značenju kao "dezideologizacija”, kako bi se kritizirali oni državni oblici koji počivaju na ideološkim, a ne demokratskim načelima.

5 Proces sekularizacije u tom se kontekstu sagledava kroz teoriju Petera Bergera. Sekularizacija za Bergera znači i krizu vjerodostojnosti religije, odnosno raspad vjerodostojnosti tradicionalnih religijskih određenja stvarnosti. Za Petera Bergera, osim sekularizacije društva i kulture suvremenoga Zapada, razvija se i sekularizacija svijesti, odnosno raste broj onih pojedinaca čiji svjetonazori više nisu vezani uz religijske interpretacije (Berger, 1990,107-135).

6 »Usp. Litterae encyclicae Ecclesiam suam de quibus viis catholicam Ecclesiam in praesenti munus suum exsequi oportet, 6 augusti 1964, AAS 56 (1964), str. 609-659 (usp. EV II., str. 163-210). U trećem poglavlju Pavao VI. govori o dijalogu sa svijetom — sa svim društvenim klasama, sa svim kategorijama ljudi: djecom, mladima, učenjacima, radnicima, umjetnicima, političarima i ljudima na vlasti (usp. EV II., str. 189-210)« (Šimić, 2008, 807, bilj. 10).

7 »'Allocutio Ss. Concilii periodo ineunte', EV I., str. 183« (Šimić, 2008, 807, bilj. 9). 
Konačno, Crkva je kroz dvije tisuće godina svojega djelovanja uvijek prolazila procese inkulturacije ${ }^{8}$ jer je navještaj Evanđelja uvijek bio u susretu s kulturama ${ }^{9}$ naroda gdje se Božja Riječ naviještala. Tomu u prilog govori i činjenica da je »u našoj hrvatskoj crkvenoj povijesti u tisućljetnoj tradiciji glagoljaškog bogoslužja, koje se već preko 400 godina služilo knjigama tiskanim glagoljicom na staroslavenskom (starohrvatskom) jeziku« (Šimić, 2008, 805) proces inkulturacije bio nazočan u svim dijelovima svijeta gdje je Crkva bila nazočna u svojem djelovanju. ${ }^{10}$ Još su kroz povijest mnogi misionari svoj put navještaja Evanđelja otvarali preko poštivanja i prihvaćanja kulturnih danosti naroda s kojima su se susretali u zemljama i krajevima gdje su djelovali. Upravo o takvom djelovanju svjedoče i brojni crkveni dokumenti koji govore o prihvaćanju različitih kultura i načinu kako se odnositi prema njima definirajući kulturu kroz njezinu antropološku i klasičnu dimenziju.

\section{Uputa o pastoralnoj brizi za migrante}

Djelovanje svake hrvatske katoličke misije u svijetu u kojem migracijski valovi jačaju i mijenjaju kulturološke mape društva usmjereno je prema različitim oblicima skrbi. U tom smislu treba spomenuti najvažnije dokumente koji reguliraju pastoralnu skrb među katoličkim migrantima. Prema Vladimiru Stankoviću postoji sedam glavnih dokumenata našega vremena, za koje autor smatra da su važni kada je riječ o iseljeničkim pitanjima, a neke smo već u prethodnim poglavljima spomenuli. To su: 1. apostolska konstitucija Exsul familia, 2. motuproprio Pastorali migratorum cura, 3. Instructio de pastorali migratorum cura, 4. motuproprio Apostolicae caritatis, 5. pismo biskupskim konferencijama $O$ Crkvi u svijetu u pokretu - Chiesa e mobilita umana, 6. enciklika Laborem exercens i 7. novi kodeks kanonskoga prava (Stanković, 1980).

Od navedenih dokumenata posebno treba istaknuti dokument Instructio de pastorali migratorum cura. Riječ je o Uputi o pastoralnoj brizi za migrante, koju je Sveta Stolica, odnosno njezina Sveta kongregacija za biskupe, objavila 22. ko-

8 Josip Šimić navodi kako su Drugi vatikanski koncil i brojni kasniji dokumenti i izjave Pavla VI., te još više Ivana Pavla II., govoreći o evangelizaciji i katehezi, posebno naglašavali važnost ispravnoga susretanja i prihvaćanja različitih autohtonih kultura u procesu koji je krajem 19. stoljeća nazvan akulturacijom, a danas ga nazivamo inkulturacijom (Šimić, 2008, 806).

9 »Općenito riječ 'kultura' označuje sve ono čime čovjek izgrađuje i razvija mnogostruke svoje duševne i tjelesne darove te nastoji da spoznajom i radom sebi podvrgne svijet; čini sve čovječnijim društveni život, i to u obiteljima kao i u cijelom građanskom društvu, moralnim napretkom i napretkom institucija; konačno, tokom vremena izražava, saopćuje i čuva u svojim djelima velika duhovna iskustva i težnje da služe napretku mnogih, dapače i cijelog čovječanstva. Prema tome, ljudska kultura sadrži nužno povijesni i socijalni aspekt te ta riječ često poprima sociološko, pače i etnološko značenje. U tom se smislu govori o više kultura (GS 53).

10 »Usp. Ivan Ćurić, 'Poslanje Crkve: Naviještanje kao inkulturacija' (I.-III.), VĐSB 118 (1990) I. dio: br. 5, str. 87-88, 93-95; II. dio: br. 6, str. 115-118; III. dio: br. 7-8, str. 138-141. Autor odmah u uvodu ističe: 'Iako je pojam 'inkulturacija' izronio iz suvremenog dinamizma Crkve, činjenica inkulturacije duboko je ucijepljena u Crkvu i stoji u njezinim temeljima, te je kao takva neodvojiva od bilo kojeg njezina događanja' (str. 87)« (Šimić, 2008, 807, bilj. 62). 
lovoza 1969. godine (Stanković, 1980, 15). Pavao VI. tu se poziva na apostolsku konstituciju Exsul Familia pape Pija XII. iz godine 1952. i na Drugi vatikanski koncil, posebno na važne dijelove enciklike Paccem in terris, gdje traži da se na tim temeljima iznova razmotri i posuvremeni katoličko dušobrižništvo za selioce (Stanković, 1980, 15). Uputa sadržava opća načela crkvenoga djelovanja u pastoralnoj skrbi za selioce, razlikujući uzroke političke, ekonomske i kulturne naravi selidbe, te stavljajući dostojanstvo osobe kao temeljno pravo. Tu se posebno ističe važnost činjenice, koja danas u djelovanju katoličkih misija predstavlja osnovu djelovanja, a to je briga za duhovno nasljeđe i vlastitu kulturu selilaca, njihov narodni jezik i običaje: »Migranti sa sobom nose svoj način mišljenja, vlastiti jezik, vlastitu kulturu i vlastitu religiju. Sve to sačinjava duhovnu baštinu misli, tradicije i kulture, koja će potrajati ii izvan domovine. Posvuda treba voditi računa o toj baštini. Ne smijemo pri tom posljednje mjesto dati materinskom jeziku migranata pomoću kojega oni izražavaju mentalitet, oblike mišljenja i kulture i sam karakter svog duhovnog života« (Stanković, 1980, 15).

U svjetlu takva promišljanja Uputa sadržava važnu dimenziju odnosa prema domovini. Naime, prema Vladimiru Stankoviću, pravo na domovinu i pravo na seljenje proširuje se tako da je moguće ne samo prostorno prelaziti u novu sredinu, nego postajati članom dviju domovina, gdje se ta dva domoljublja, odnosno te dvije domovine nipošto ne isključuju (Stanković, 1980, 16). Iz takva tumačenja proizlazi da domovina pripada svima onima koji u njoj žive prihvaćajući sve njezine vrijednosti, njezin jezik, kulturu, povijest, kao i pojedince kojima je ta domovina vlastita.

U tom kontekstu treba naglasiti da se djelovanje hrvatske inozemne pastve ne može ispravno ocijeniti i opisati isključivo u optici nabrojenih crkvenih dokumenata jer danas imamo i niz različitih društveno uvjetovanih čimbenika koji definiraju nove oblike djelovanja inozemne pastve.

\section{Zaključak}

Izvornost suvremenoga selilaštva danas treba sagledavati kroz prizmu biblijske stvarnosti. Tu nas najprije Evanđelje povezuje sa selilaštvom dajući nam sliku bijega nazaretske obitelji i djeteta Isusa u Egipat, odakle se iz te tuđe zemlje vraćaju u svoju zemlju. Katolička crkva je danas u obzoru svjetskih migracijskih procesa svjesna selilačke stvarnosti i njezine uloge koja joj tu pripada. Ulazeći u suvremene probleme koji prate svakoga selioca, Crkva nastoji kroz dušobrižno služenje promatrati odnos vjernika i bogoštovlja, kao i sve ljudske probleme koje izaziva pojava seljenja. Oni se u prvom redu odnose na dušobrižništvo, odnosno nastojanje da se i sami selioci osjete kao navjestitelji Evanđelja. U tom kontekstu postaje jasna uloga Crkve, a to je da je ona logičan izraz one brige i ljubavi koju utjelovljeni Bog pokazuje prema svakom čovjeku.

U takvom promišljanju Vladimir Stanković posebno ističe činjenicu da od konca 19. stoljeća do početka 20. stoljeća ni kod najviše crkvene uprave u Rimu, kao ni kod mjesnih Crkava zemalja iseljenja i zemalja useljenja, nije postojala 
današnja svijest o potrebi specijaliziranoga dušobrižništva za suvremeni globalni svijet, pa se dosljedno tomu nisu mogle ni razviti odgovarajuće strukture. Ta činjenica, naravno, ne govori o tom da je Crkva pasivno stajala pred masovnim migracijskim fenomenima, baš kao što ne stoji ni danas, nego naprotiv, danas inozemna pastva postaje proaktivna prateći upravo fenomene koji sve više idu u smjeru pomaganja i pripadnicima nekršćanskih religija, stvarajući nove oblike suživota koji će omogućiti i odrediti nove načine ekumenskoga zbližavanja i naviještanja Evanđelja.

\section{Literatura:}

Berger, Peter L. (1990). The Sacred Canopy: Elements of a Sociological Theory of Religion. New York: Anchor Books.

Božić, Saša (2004). Nacionalizam — nacija, "transnacionalizam" — "transnacija”: mogućnosti terminološkog usklađivanja. Revija za sociologiju, 35(3-4), 87-203.

Castells, Manuel (2000). Uspon umreženog društva. Zagreb: Golden marketing.

Erga migrantes caritas Christi (2004). Pontifical Council for the Pastoral Care of Migrants and Itinerant People, Instruction: Erga migrantes caritas Christi: (The love of Christ towards migrants). Vatican City. URL: http://www.vatican.va/roman_curia/pontifical_councils/migrants/documents/rc_pc_migrants_doc_20040514_erga-migrantescaritas-christi_en.html (19.09.2019.)

GS. Gaudium et spes. Drugi vatikanski koncil, Pastoralna konstitucija Gaudium et spes o Crkvi u suvremenom svijetu. U: Josip Turčinović (ur.), II vatikanski koncil: Dokumenti: Latinski i hrvatski (str. 620-768). Zagreb: Kršćanska sadašnjost, 1970.

Hervieu-Léger, Danièle (2000). Religion as a Chain of Memory. Cambridge: Polity Press.

Iannaccone, Laurence R. (1992). Religious Markets and the Economics of Religion. Social Compass, 39(1), 123-131.

Kalmijn, Matthijs (2003). Country Differences in Sex-Role Attitudes: Cultural and Economic Explanations. U: Wilhelmus Antonius Arts, Jacques Hagenaars i Loek Halman (ur.), The Cultural Diversity of European Unity: Findings, Explanations and Reflections from the European Value Study (str. 311-337). Leiden: Brill.

Kuti, Simona (2012). Koncepti transnacionalnih socijalnih prostora i polja u istraživanju migracijskih i postmigracijskih procesa. Migracijske i etničke teme, 28 (2), 119-141.

Levitt, Peggy; Glick Schiller, Nina (2004). Conceptualizing Simultaneity: A Transnational Social Field Perspective on Society. International Migration Review, 38(3), 1002-1039.

Mesić, Milan (2007). Metodološki kozmopolitizam versus metodološki nacionalizam. Revija za sociologiju, 38(1-2), 71-83.

Pries, Ludger (2001). The Approach of Transnational Social Spaces: Responding to New Configurations of the Social an the Spatial. U: Ludger Pries (ur.), New Transnational Social Spaces: International Migration and Transnational Companies in the Early Twenty-first Century (str. 3-33). London: Routledge.

Pries, Ludger (2005). Configurations of Geographic and Societal Spaces: A Sociological Proposal between "Metodological Nationalism" and the "Spaces of Flows". Global Networks, 5(2), 167-191.

Pries, Ludger (2008a). Transnational Societal Spaces: Which Units of Analysis, Reference and Measurement. U: Ludger Pries (ur.), Rethinking Transnationalism: The MesoLink of Organisations (str. 1-20). London: Routledge. 
Pries, Ludger (2008b). Die Transnationalisierung der soialen Welt: Sozialräume jenseits von Nationalgesellschaften. Frankfurt am Mein: Suhrkamp.

Stanković, Vladimir (1991). Pastoralni problemi i perspektive naših iseljenika. U: Franjo Topić (ur.), Teološke teme (str. 436-458). Sarajevo: Vrhobosanska visoka teološka škola.

Stanković, Vladimir (ur.) (1980). Katolička crkva i Hrvati izvan domovine. Zagreb: Vijeće BK za Hrvatsku migraciju.

Šimić, Josip (2008). Kultura i inkulturacija u učenju i djelovanju Katoličke crkve od II. vatikanskog sabora. Filozofska istraživanja, 28(4), 805-822.

Waldinger, Roger i Fitzgerald, David (2004). »Transnationalism in Question«, American Journal of Sociology, 109 (5): 1177-1195.

Welcoming Christ (2013). Pontifical Council for the Pastoral Care of Migrants and Itinerant People i Pontifical Council Cor Unum, Welcoming Christ in Refugees and Forcibly Displaced Persons: Pastoral Guidelines. Vatican City. URL: http:/www.vatican.va/ roman_curia/pontifical_councils/corunum/corunum_en/pubblicazioni_en/Rifugiati-2013-INGL.pdf (19.09.2019.)

Aspects of Pastoral Care in the Catholic Church Today

Andreja Sršen*

Summary:

As is evident in the many centuries of migration of the Croatian people, and also throughout all of history up until the present day, the presence of the Catholic Church is revealed in her various activities. Furthermore, keeping in mind new global migration processes, the pastoral activities of the Catholic Church today may be narrowed down to missionary activity, caritative practice and social pastoral activity. Today, since faith and culture are being confronted with various social rifts, the contemporary evangelizing missionary is impelled to regard culture as a means by which religious norms may be applied and social spheres which need to be Gospel-permeated may be determined. However, with the development of modern society come changes , not only in religious practices and in the declining influence of religious institutions, but also, first and foremost, in the declining importance of the community in highly organized social systems. Thus, a new understanding of the Catholic Church and her pastoral activity takes its place in determining the significance of the migrant's position in the modern world. Precisely this sort of person, lodged in a socio-psychological rift, needs the continuing task of the mission to be his integration into a new society on the functional, social, emotional and cultural levels. Throughout the two thousand years of her activity, the Church has constantly undergone enculturation processes, since the spreading of the Gospel implied an encounter with the cultures of nations in which the Word of God was being preached. Throughout history many missionaries opened the way to evangelization by respecting and accepting cultural

* Andreja Sršen, Assistant Professor, Croatian Studies, University of Zagreb. Address: Borongajska cesta 83d, 10000 Zagreb, Croatia. E-mail: asrsen@hrstud.hr 
givens of the people whom they encountered in the countries and regions where they worked. Numerous Church documents testify to this sort of activity for they speak of accepting various cultures and ways to relate to them by defining culture in its anthroplogical and classical dimension. The right to a country and the right to migrate is spreading such that it is possible not only to settle in a new environment, but also to be a member of two countries in such a way that two patriotisms do not exclude each other. As regards the contemporary migration phenomenon which has biblical roots, the Catholic Church is aware that this is an examination of conscience both for those migrating, and for those taking in migrants. Thus, Croats abroad become proactive as they observe phenomena which require them to provide assistance to members of non-Christian religions and thus to create new forms of coexistence which will in turn make possible new forms of ecumenical rapprochement and preaching of the Gospel.

Key words: Catholic Church; Gospel; pastoral activity; migration; homeland; Croats abroad 